\title{
Analysis of Urban Public Spaces' Wind Environment by Applying the CFD Simulation Method: a Case Study in Nanjing
}

\author{
Xiaoyue Wang ${ }^{\mathrm{AB}}$, Fang $\mathrm{Liu}^{\mathrm{AC}}$, Zhen $\mathrm{Xu}^{\mathrm{A}^{*}}$ \\ Received: November 30, 2019 | Revised: December 28, 2019 | Accepted: December 29, 2019 \\ DOI: $10.5937 / g p 23-24249$
}

\begin{abstract}
The increase in the density of high-rise buildings is making urban air flow increasingly complex, and the wind environment conditions in urban public spaces are considerably changing. At present, few studies focus on the relationship between wind environment and the master plan of urban public spaces or attempt to improve the wind environment of public spaces from a landscape design perspective. To resolve this gap in information, this study explored the relationship among wind speed, seasonal comfort level in Nanjing, and different types of planting patterns. Computational fluid dynamics (CFD) software was used to quantify the seasonal wind environment of Xuanwumen Square in Nanjing. Three planting designs were created on the basis of the results, and their CFD results were compared among one another. Comparison results show that the second planting design provides the best wind environment, and its comfort levels are 2.26, 1.92, and 2.09 out of 5 in winter, summer, and total. Understanding of the relationship among different landscape designs and their impacts on wind environment supports designers in improving the wind environment of Xuanwumen Square in Nanjing. This study provides new insights into relating urban public space design with the quantitative research of wind environment in the future.
\end{abstract}

Keywords: CFD simulation; wind environment; urban public space; landscape quantitative analysis

\section{Introduction}

The increasing degree of urbanization has made the wind environment inside the city increasingly complex. This situation is caused not by the macro-level environmental changes but by the near-ground environmental changes, that is, the local climate and environment changes formed by the complexity of public space form. The specific characteristics are described as follows: the city is in a quiet and windless state all the year round, the atmospheric flow is difficult, the local high temperature anomaly is increasing, and the aggravation of fog and haze directly affects people's living standard (Feng \& Chu, 2017). Previous studies on microclimate have determined outdoor environmental comfort by black-ball temperature, airflow velocity, and relative humidity of air (Chen \& Yang, 2014; Zhang, 2012; Zuo \& Chu, 2003). Among them, airflow velocity, that is, the wind environment, has the most direct and significant relationship with the spatial form, that is, the most easily changed by human regulation. The previous research method of wind environment is mainly based on field test. Domestic scholars have combined it with various influencing factors

\footnotetext{
A Nanjing Forestry University, College of Landscape Architecture, 159 Longpan Rd, Nanjing 210037

B University of California, Berkeley, College of Environmental Design

C Politecnico di Milano, School of Architecture Urban Planning Construction Engineering

* Corresponding author: Zhen Xu, e-mail: xuzhen@njfu.edu.cn
} 
to study wind environment. Hong and Lin discussed the relationship between wind and plants by reducing the influence of winter wind speed in the field test of a residential area in Beijing (Hong \&Lin, 2014). They found that the layout optimization and improvement of a green space has also been explored in the numerical simulation analysis of urban outdoor wind environment. Ke and Sang introduced the leaf surface index to simulate and test the windbreak effect of small forest belts on the basis of on the urban street valley model; this model can reasonably simulate the dynamic shelter effect of shelterbelts (Ke \& Sang, 2007). On this basis, the wind environment of urban public spaces has attracted considerable attention.

Quantitative research emerges as the times require, and scholars at home and abroad have extensively used computational fluid dynamics (CFD). Dynamics (CFD simulation) method quantifies the wind environment of public spaces, such as parks, residential green areas, and squares. Li and Zhao used CFD technology to explore the relationship among residential building density, building height, windward area, and average wind speed in residential planning (Li \& Zhao, 2010). Liu used CFD method to simulate the microclimate of the planned buildings, predict the impact of the planning scheme on the microclimate of buildings and blocks, and quantitatively analyze the impact of the planning scheme on the space to optimize the layout (Liu, 2005).

Under the background of rapid urbanization, improving the urban public space environment using wind environment and allocating plant landscape scientifically and effectively are important tasks. Therefore, this study examines the wind environment of a city square, which is a core area of urban public activities. Improvement of the wind environment through different plant barriers is explored through the analysis and evaluation of the existing wind environment conditions of the square in summer and winter. The envi- ronmental comfort levels using different planting strategies are also compared. Three schemes are suggested for improving Xuanwumen Square in Nanjing. This work provides a new idea for the quantitative study of urban public space wind environment in the future.

\section{Site analysis}

The total area of Xuanwumen Square in Nanjing City is 1.44 ha, and the square is close to Xuanwumen Station of Line 1 of Metro, Xuanwu Lake Park in the East and Nanjing City Center in the west. Xuanwumen Square, which is a public space of urban traffic hub, is surrounded by many large public buildings. The square is located near Xuanwu Lake Park, which is a large area of water. The high density of the city changes the air flow of the plot rapidly and complicates the wind environment conditions. Thus, the plot is located near Xuanwu Lake Park. Wind environment has high research value.

Nanjing belongs to the humid climate of subtropical region. Under the control of westerly circulation, the monsoon is remarkable, the seasonal phenomena change distinctly, the dominant wind direction is northeast and southwest, and the southeast wind is dominant in summer. Given the climate characteristics of cold winter and hot summer in subtropical monsoon climate zone, the dominant wind direction and the average wind speed downward of the dominant wind on summer solstice and winter solstice are selected as the parameters of wind environment simulation. The CSWD format meteorological data file provided by China Meteorological Data Network indicated that the dominant wind direction in summer is $20^{\circ} \mathrm{SE}$, the average wind speed of $1.5 \mathrm{~m}$ pedestrian height is approximately $2 \mathrm{~m} / \mathrm{s}$, the main wind direction in winter is $70^{\circ} \mathrm{NE}$, and the average wind speed at $1.5 \mathrm{~m}$ pedestrian height is $4 \mathrm{~m} / \mathrm{s}$, which is used as the wind environment simulation parameter (Xu \& Han, 2018). On the basis of the latest topographic maps in ARCGIS and

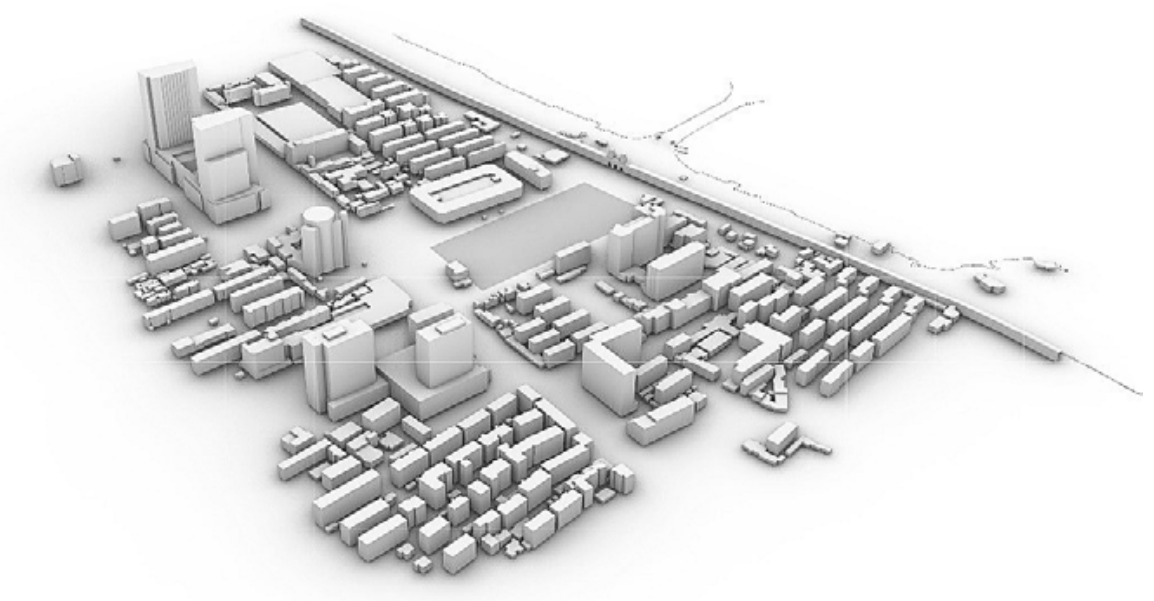

Figure 1. 3D model of Xuanwumen Square 
many field investigations in March 19, Rhino software is used to build ${ }_{3} \mathrm{D}$ models of site structures (such as city walls) and buildings (Fig. 1). As observed, the use of flat or sloping roof slightly affects the simulation results of this large-scale downwind environment. Thus, the sloping roof is simplified to flat roof. The red plot in the picture is Xuanwumen Square.

\section{Computational Fluid Dynamics}

CFD is a software used as a simulation tool. CFD has the advantages of low cost, good simulation conditions, good repeatability and easy control compared with observation and wind tunnel tests. The author mainly discusses the influence of wind speed on users of public space rather than the study of space flu- ids. Thus, the analysis is performed through a $2 \mathrm{D}$ cross-sectional view at $1.5 \mathrm{~m}$. The evaluation method is based on CFD wind running results and wind environment comfort evaluation grade of Nanjing. The specific steps are discussed as follows:

The simulation uses a new generation of CFD simulation software called XFlow developed by Next Limit Technology to simulate wind speed. Compared with wind tunnel experiments and field measurements, XFlow simulation can predict wind conditions of different scales well. The analysis using XFlow has been recognized in Japan, China, and Korea. The non-network method in XFlow is based on particles and has a complete Lagrange function, which has great advantages over other CFD simulation software in the past.

\section{Data and methods}

1) The influencing factors of the square wind environment are analyzed. The ideal square wind environment has good ventilation and pollutant diffusion function in summer and the ability to resist the cold wind in winter. Accordingly, the wind environment in different seasons can provide better comfort. As shown in Table 1 , the factors that influence the wind can be summarized as the following six aspects (Li et al., 2010). The transformation of space elements is the most possible and is thus mainly discussed in this paper.

Three factors are summarized in Table 2. Among them, plant barrier has the material form of enclosing and dividing urban square space, creating good square space form, effectively blocking, reasonably guiding, and properly reducing wind. This approach has relatively low cost, high environmental benefit, and good visual effect. Therefore, this study comprehensively analyzes plant-related strategies.

In the various forms of garden planting based on previous studies (Huang, 2016) and field observations, six typical models are selected for simulation experiments in the horizontal direction to observe the different planting forms around the impact of the wind environment. Necessary simplification of the plant model is applied in the experiment. The wind tunnel test conducted by GreenS showed that the tree shape is simplified in the wind tunnel test of each canopy shape (Greens, 1995; Liu \& Si, 2018). The simplified shape is simple, conducive to calculation, and of excellent convergence compared with other models (Zhang, 2015). Accordingly, the current simulation experiment set a single plant to a long elliptical crown

Table 1. Factors of square wind comfort and their implementation phrases

\begin{tabular}{|l|l|l|}
\hline Influencing factor & Implementation phase & $\begin{array}{l}\text { Whether to } \\
\text { adopt or not }\end{array}$ \\
\hline Urban Road Layout & Urban Overall Planning and Reform & $\times$ \\
\hline Blocks and Buildings & Phase of Urban Overall Planning and Reform \\
\hline $\begin{array}{l}\text { Surrounding Architectural } \\
\text { Layout }\end{array}$ & $\begin{array}{l}\text { Planning and Design Stage of New Buildings and Reconstruction Stage of } \\
\text { Existing Buildings }\end{array}$ & $\times$ \\
\hline Space Elements of Square & Design Stage of New Square and Reconstruction Stage of Existing Square & $\quad \sqrt{ }$ \\
\hline Functional Activity Layout & Design Stage of New Square and Reconstruction Stage of Existing Square & $\times$ \\
\hline Substantive Elements of Square & Design Stage of New Square and Reconstruction Stage of Existing Square & $\times$ \\
\hline
\end{tabular}

Table 2. Factors of space elements of square

\begin{tabular}{|l|l|c|}
\hline Influencing factor & Implementation phase & $\begin{array}{l}\text { Whether to } \\
\text { adopt or not }\end{array}$ \\
\hline Terrain barrier & Tuqiu, Sunken Square & $\times$ \\
\hline Plant barrier & Arrangement, clustering, etc. & $\sqrt{ }$ \\
\hline Building and infrastructure Barrier & Windbreak fences (Ivana et al., 2017), sculpture, etc. \\
\hline
\end{tabular}



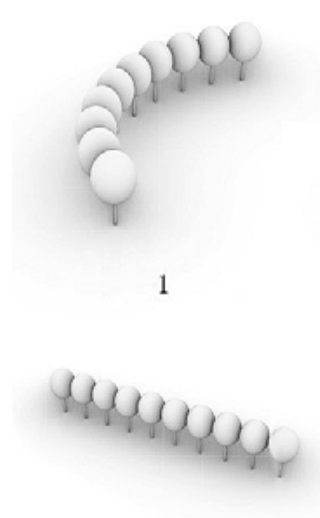

4
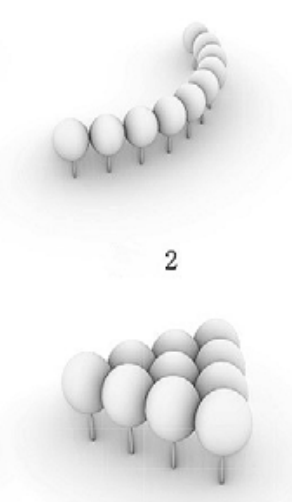

5

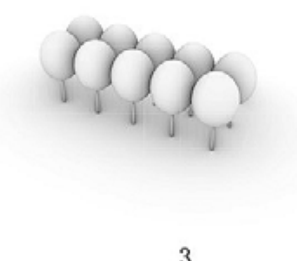

3

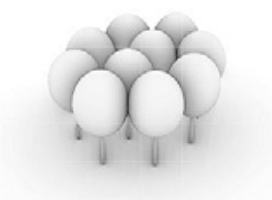

6

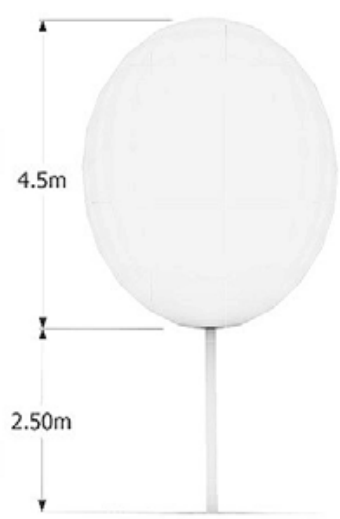

Figure 2. Planting patterns affecting wind environment

with a height of $7 \mathrm{~m}$, a branch height of $2.5 \mathrm{~m}$, a canopy height of $4.5 \mathrm{~m}$, and a width of $3 \mathrm{~m}$. The tree is at the center of the calculation area. Modeling with $\mathrm{Au}-$ toCAD and exporting the stl format further reduce the error caused by the reversal of the front and back.

2) Wind environment rating is classified. In different cities, the wind environment can meet people's needs at different temperatures and humidity. The wind speed of body comfort differs. According to the relationship between temperature and humidity, the formula for calculating body comfort is:

$$
\begin{aligned}
& S S D=(1.818 \cdot t+18.18) \cdot(0.88+0.002 \cdot f)+ \\
& +(t-32) /(45-t)-3.2 V+18.2,
\end{aligned}
$$

where $t$ is the temperature, $f$ is the relative humidity, and $V$ is the wind speed.

The climatic data in this study are based on the cumulative monthly mean temperature $\left({ }^{\circ} \mathrm{C}\right)$ and wind speed (m/s) from 1982 to 2012 in Nanjing. With relative humidity (\%), the data come from China Meteorological Science Data Sharing Service Network and have high reliability (Tang et al., 2014). In Nanjing, the average temperature from June to August is $26.9^{\circ} \mathrm{C}$ and the average relative humidity is $78.4 \%$. In December to February, the average temperature is $4.1{ }^{\circ} \mathrm{C}$ and the average relative humidity is $72.7 \%$. On this basis, the human comfort index of Nanjing can be classified as follows:
Table 3. Summer wind environmental comfort level

\begin{tabular}{|c|c|}
\hline Wind speed $(\mathrm{m} / \mathrm{s})$ & Summer ssd \\
\hline $5.44<\mathrm{V} \leq 8.86$ & $59-70$ \\
\hline $3.88<\mathrm{V} \leq 5.13$ & $71-75$ \\
\hline $2.63<\mathrm{V} \leq 3.56$ & $76-79$ \\
\hline $0.75<\mathrm{V} \leq 2.31$ & $80-85$ \\
\hline $\mathrm{V} \leq 0.43$ & $86-88$ \\
\hline
\end{tabular}

Table 4. Winter wind environmental comfort level

\begin{tabular}{|c|c|}
\hline Wind speed $(\mathrm{m} / \mathrm{s})$ & Winter ssd \\
\hline $\mathrm{V} \leq 0$ & $59-70$ \\
\hline $\mathrm{V} \leq 0$ & $51-58$ \\
\hline $0<\mathrm{V} \leq 1.50$ & $39-50$ \\
\hline $1.81<\mathrm{V} \leq 5.56$ & $26-38$ \\
\hline $5.88<\mathrm{V}$ & $0-25$ \\
\hline
\end{tabular}

3) Colors are used to distinguish the active blocks of different wind speed levels in Xuanwumen Square for illustrating the problem intuitively based on the comfort level of winter and summer wind environment in Tables 1 and 2. The color and corresponding wind speed are shown in Table 3. Inspired by previous research (Zeng, 2019), the square is evenly partitioned using 50×20 fishnet grid in ArcGIS; then, the wind speed simulated by CFD is graded to fill in the corresponding color. A dark color corresponds to low comfort.

Table 5. Evaluation grade of wind environment comfort in Nanjing

\begin{tabular}{|l|c|c|c|}
\hline Level of comfort & Summer wind speed $(\mathrm{m} / \mathrm{s})$ & Winter wind speed $(\mathrm{m} / \mathrm{s})$ & Color \\
\hline Level 1 very suitable & $5.44-8.86$ & 0 & \\
\hline Level 2 suitable & $3.88-5.13$ & 0 & \\
\hline Level 3 normal & $2.63-3.56$ & $0-1.50$ & \\
\hline Level 4 unsuitable & $0.75-2.31$ & $1.81-5.56$ & \\
\hline Level 5 strongly inappropriate & $0.00-0.43$ & $5.88-\infty$ & \\
\hline
\end{tabular}




\section{Results and discussion}

\section{Wind Environment Assessment of Xuanwumen Square}

After the significance of microclimate in urban public space is clarified and the effects of different planting forms on the microenvironment are explored, this study conducts an environmental simulation of $\mathrm{Xu}$ anwumen Square in Nanjing and analyzes the existing sites in the following sub regions to provide a quantitative theoretical basis.

In the previous model preparation, the object is a city square and the scope is large. Thus, the modeling reference standard of the Japan Institute of Architects is adopted, that is, buildings within the 1-2 ha area around the target building should be clearly modeled. CFD software is used to simulate the wind environment evaluation of Xuanwumen Square in the surrounding environment, and at least one block model is extended in each direction outside the area. Technically, 3D modeling of buildings, structures (such as city walls), and major terrain is performed in conjunction with field research in AutoCAD and Rhino software.

In the calculation setting, the wind environment model still adopts the $3 \mathrm{D}$ kernel mode, and the calculation method adopts the external flow calculation.
The resolution is controlled within $0.5 \mathrm{~m}$ to ensure the accuracy of the results. At the end of the calculation, the $2 \mathrm{D}$ image interception at a height of $1.5 \mathrm{~m}$ is performed in the post-processing section. The reason is that the wind environment at the height of $1.5 \mathrm{~m}$ is closest to the pedestrian height. Accordingly, the impact on residents is most evident.

In analyzing wind speed, this study selects the average wind speed as described above, that is, the winter solstice is $4 \mathrm{~m} / \mathrm{s}$, the wind is upward, and the dominant wind direction in winter is north to east. After CFD simulation, the impact of the surrounding environment of Xuanwumen Square on the wind environment of the research block is obtained as follows:

In the winter in Nanjing, the too high wind speed causes discomfort. Figure 4 shows the winter wind environment in the activity areas.

The wind speed is studied at $2 \mathrm{~m} / \mathrm{s}$ in the previous summer solstice, and the dominant wind direction in the summer is southeast to south. The summer impact of the surrounding environment of Xuanwumen Square on the study of the wind environment of the plot is obtained as follows on Fig. 5.

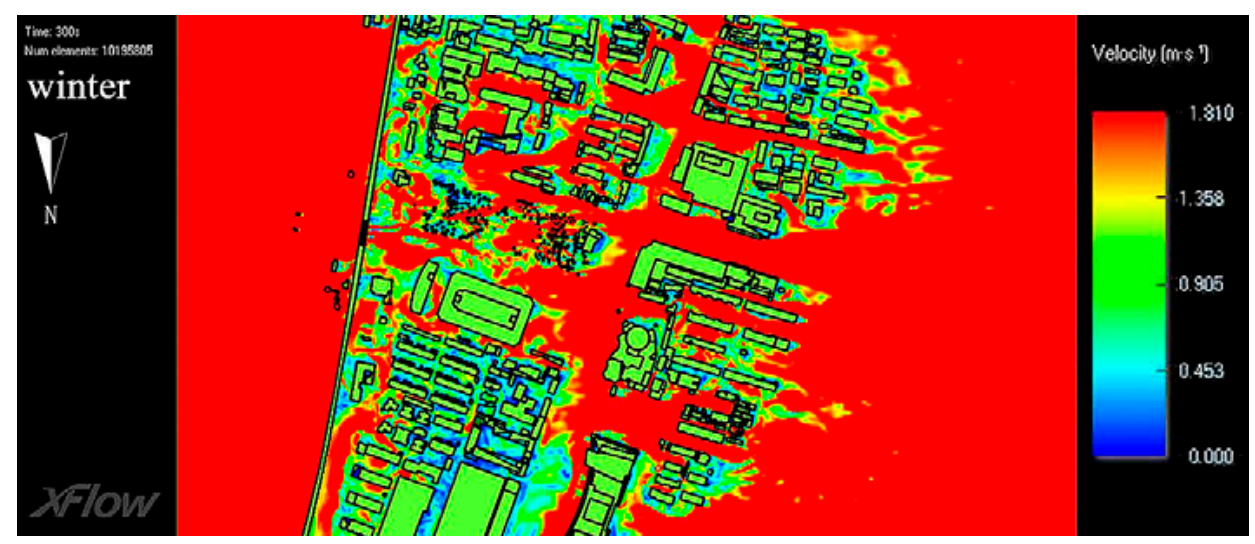

Figure 3. Current wind environment of Xuanwumen Square in winter

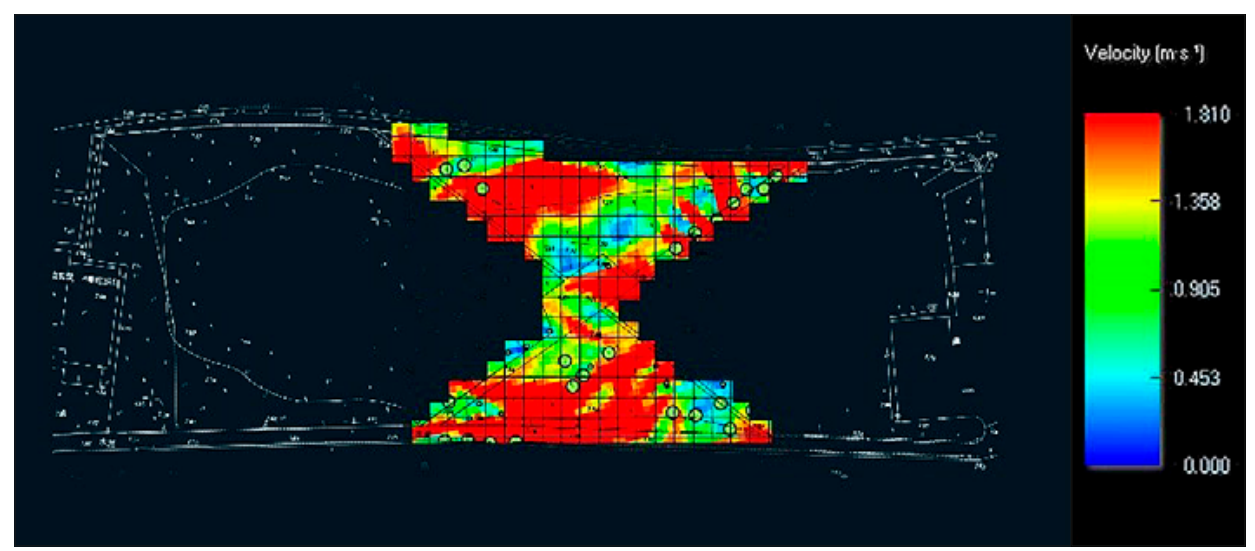

Figure 4. Winter wind environment in resting and walking areas 


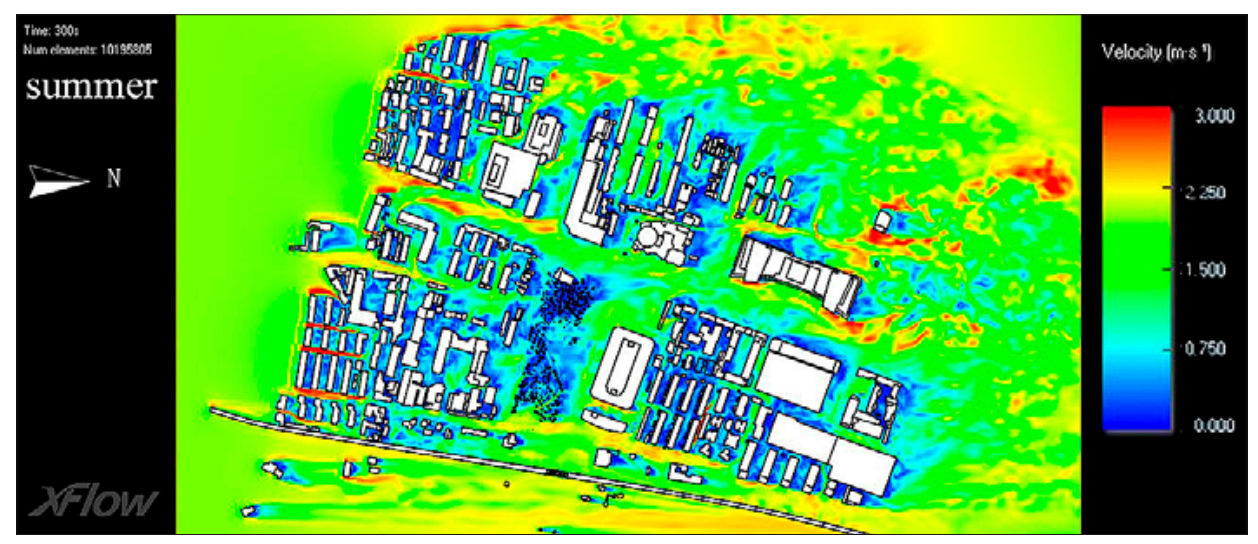

Figure 5. Wind environment of Xuanwumen Square in summer

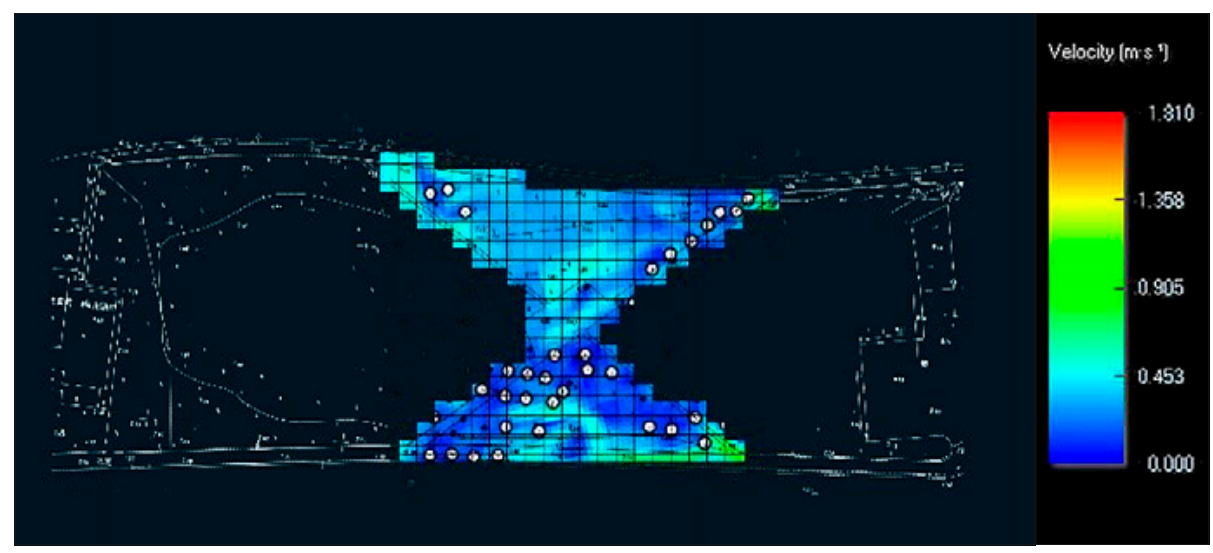

Figure 6. Summer wind environment in resting and walking areas

In the summer of Nanjing, the too low wind speed does not easily flow out, the pollutants are not easy to spread, and the human body feels comfortable.

\section{Plant barrier mode assessment}

Garden plants are planted in various forms, each of which has different effects on the wind environment. This work studies six different types to determine the influence of plant communities in planting forms on the surrounding wind environment. The height of the tree simulated in this study is $7 \mathrm{~m}$. The height of the branches is set to $2.5 \mathrm{~m}$, the height of the canopy is set to $4.5 \mathrm{~m}$, and the width is set to 3 $\mathrm{m}$. The analysis method of wind environment model in $3 \mathrm{D}$ kernel mode uses the outflow algorithm. For accurate imagery, the resolution is controlled to 0.5 $\mathrm{m}$. The calculus ends in the post-processing section at a height of $1.5 \mathrm{~m}$. The wind environment at $1.5 \mathrm{~m}$ height is closest to the pedestrian height. Thus, its impact on residents is the most evident. This study selects the average wind speed of the winter solstice mentioned above and uses $4 \mathrm{~m} / \mathrm{s}$ as the parameter for wind speed studies. The wind speed of the plant barrier running wind in Figure 7 is $0-5 \mathrm{ra} / \mathrm{s}$. Accordingly, all the results in Figure 12 use the same legend. The $300 \mathrm{~s}$ CFD simulation is conducted to ensure the accuracy of the results. The impact of six dif- ferent plant barriers on the wind environment is obtained as follows in Fig. 7.

The figure above shows that combination $\mathrm{A}$ is a straight line of planting. Within o-20 $\mathrm{m}$ from the tree, the wind speed is the lowest and falls below $1.265 \mathrm{~m} / \mathrm{s}$, and the branch is highly uniform. In the range of 20$40 \mathrm{~m}$, the average wind speed is approximately $2.5 \mathrm{~m} / \mathrm{s}$, and the wind speed is beyond $40 \mathrm{~m}$. The range wind speed gradually increases. The sectional view reveals that the wind speed has increased to a certain extent vertically above the trees, and the higher area is less affected than the lower area.

In combination $\mathrm{B}$, the two rows of straight-line crops formed in the downwind area have a very low wind speed. The wind shadow range is smaller than that of one row of straight-line crops, and the distribution is relatively concentrated. The average wind speed is $0.02 \mathrm{~m} / \mathrm{s}$. The area affected in the vertical direction of the facade should be larger than one line of straight planting. Therefore, increasing the number of planting rows can effectively reduce wind speed. On the basis of combinations A and B, scheme 1 is created and assessed as follows in Fig. 8.

The arc-shaped planting form of combination $\mathrm{C}$ can have the largest range of influence in the upwind direction, but the wind field characteristics under the trees are highly complicated. The gap between each 

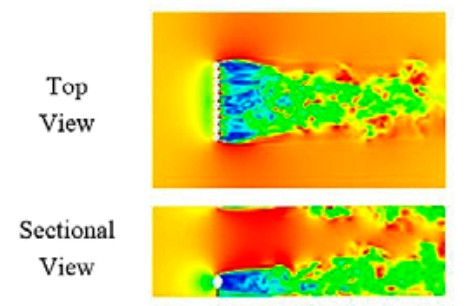

combination $\mathrm{A}$

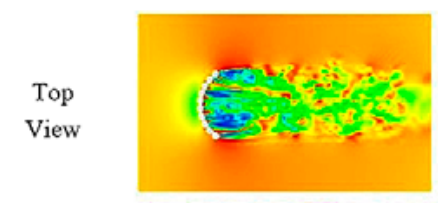

Sectional View
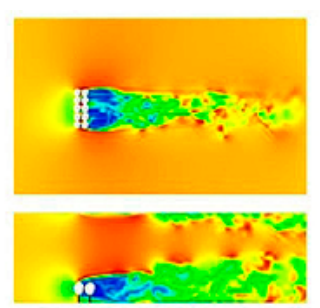

combination B
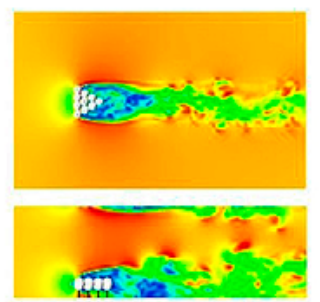

combination $\mathrm{E}$

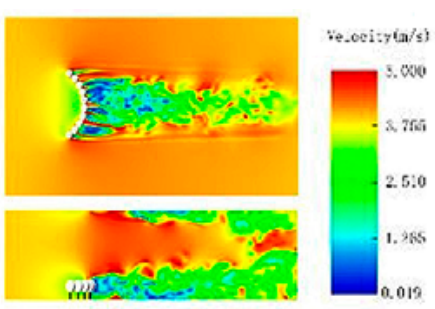

combination $\mathrm{C}$

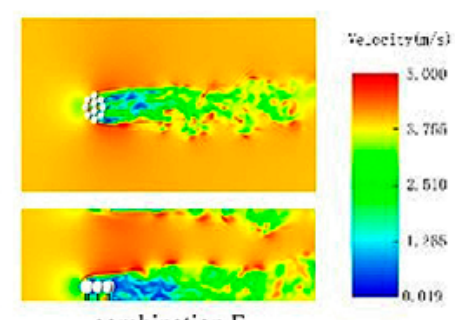

combination $\mathrm{F}$

Figure 7. Plant barrier mode assessment
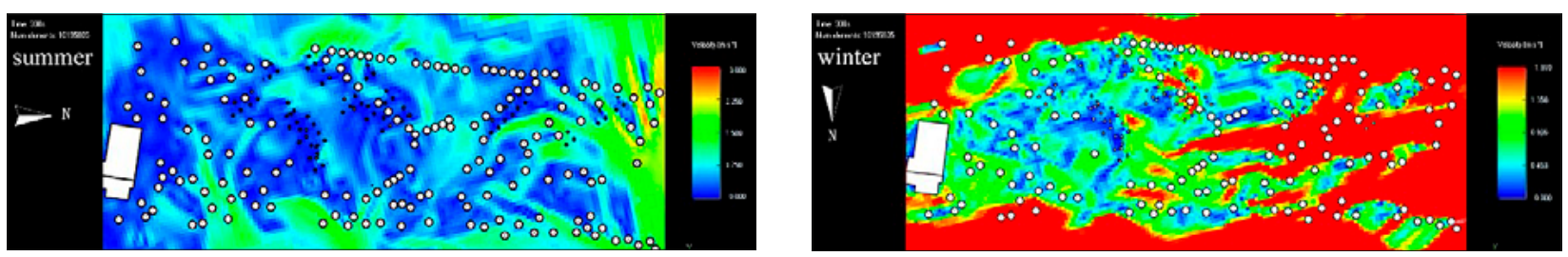

Figure 8. Summer (left) and winter (right) results of scheme 1

tree forms a high wind speed region with a length of 5-10 $\mathrm{m}$ and reaches $5 \mathrm{~m} / \mathrm{s}$. The arc-shaped planting of combination $\mathrm{D}$ also causes a narrow and high wind speed area in the gap between the trees on both sides of the tree. Accordingly, nearly $50 \%$ of the wind shadow area forms within $20 \mathrm{~m}$ of the leeward area. The two arc-shaped plantings form the smallest wind shadow area on the profile, the wind speed attenuation is not evident, and the wind blocking effect is worse than that of the row planting trees. On the basis of combinations $\mathrm{C}$ and $\mathrm{D}$, scheme 2 is created and assessed as follows in Fig. 9.
Combinations $\mathrm{E}$ and $\mathrm{F}$ are triangular and circular dense plants, respectively. The incoming wind has a similar attenuation trend in the leeward area of the trees, but the effects are not as significant as the row planting. Triangular dense planting forms a calm wind area within $30 \mathrm{~m}$ from the tree, and the area where the wind speed drops below $1.265 \mathrm{~m} / \mathrm{s} \mathrm{ex}$ ceeds $50 \%$. Among them, a clear wind shadow area is formed within the range of $20-30 \mathrm{~m}$ from the tree, and the wind speed is as low as $0.02 \mathrm{~m} / \mathrm{s}$. On the basis of combinations $\mathrm{E}$ and $\mathrm{F}$, scheme 3 is created and assessed as follows in Fig. 10.
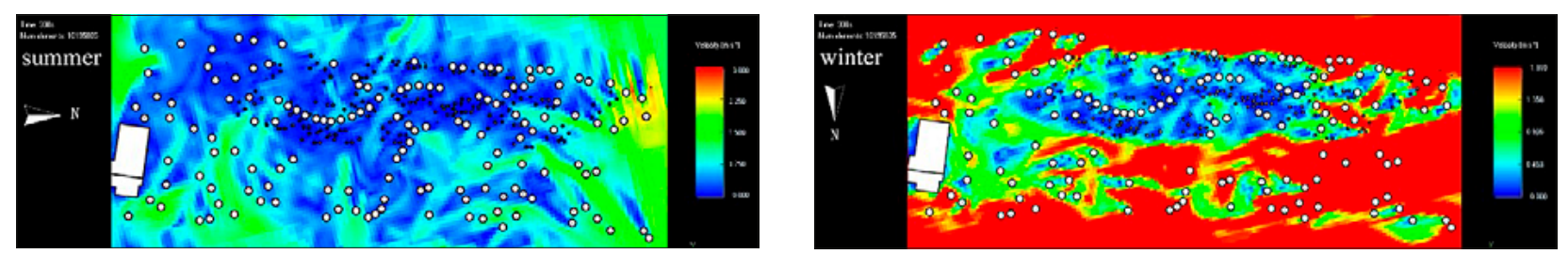

Figure 9. Summer (left) and winter (right) results of scheme 2
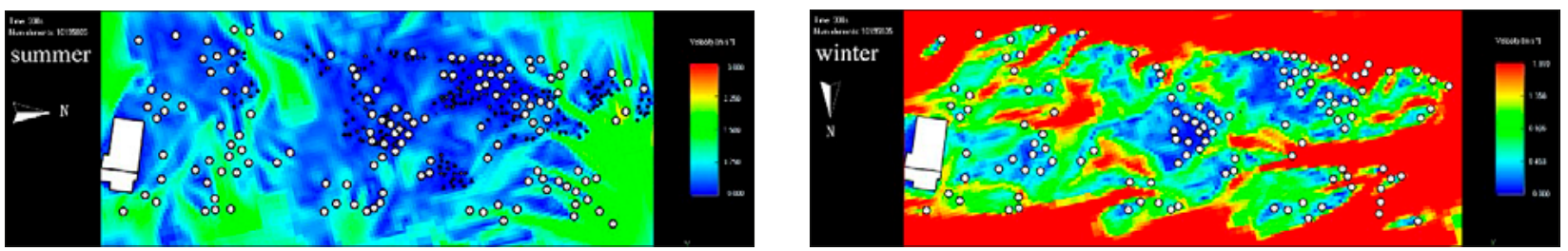

Figure 10. Summer (left) and winter (right) results of scheme 3 


\section{Comfort level of wind environment Assessment}

On the basis of the body comfort level of wind environment in Tables 1 and 2 above, this study uses $50 \times 20$ fishnet grid in ArcGIS to partition the square evenly and distinguish the blocks of different wind speed levels simulated in CFD by filling in the corresponding color of the comfort level. The two situations of winter and summer are overlaid to analyze the total comfort level for illustrating the results intuitively. A activity side and on the active lawn. The windshield effect is considered highly significant. The average comfort level in scheme 2 is the highest among the three at 1.92 out of 5 . In scheme 3 , triangular and spherical densely planted evergreen trees can only reduce the wind speed in a short distance from the downwind direction. The wind shadow area formed is smaller than those in the two other schemes, and the average comfort is lower at 1.82 out of 5 .

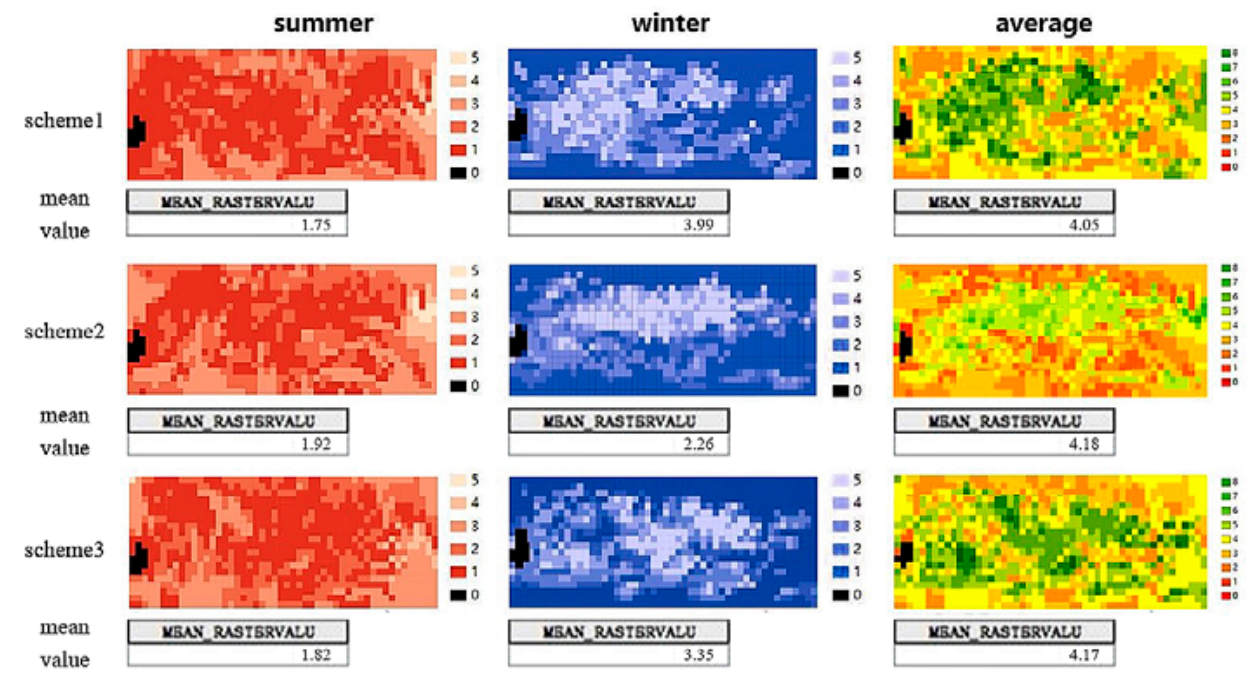

Figure 11. Comfort levels of schemes 1, 2, and 3

dark color indicates low comfort. The existing square consists of a central rest point. Overlaying the existing site plan show that the overall wind speed is high due to lack of building shelter on the northeast side in winter. Meanwhile, the air flow is blocked by dense forests in summer, thereby causing low body comfort.

In scheme 1, a linear line of evergreen trees on the north side of the activity area forms a windbreak to effectively reduce the winter wind speed, and a wind shadow area is formed in the activity space. In scheme 2 , evergreen trees are planted in a straight line on the
In summer, the southeast wind is blocked by the building on the south side. As a result, a wind shadow area and a turbulent area are formed on the square. The activity place fails to meet the comfort needs of people when they are conducting outdoor recreation activities. Three solutions are implemented on the south side to improve the aforementioned situation. Trees are evacuated and planted in the activity area, and ventilation channels are reserved for the activity space in summer. Among them, schemes 1 and 3 can achieve high average comfort levels of 3.99 and 2.35, respectively.

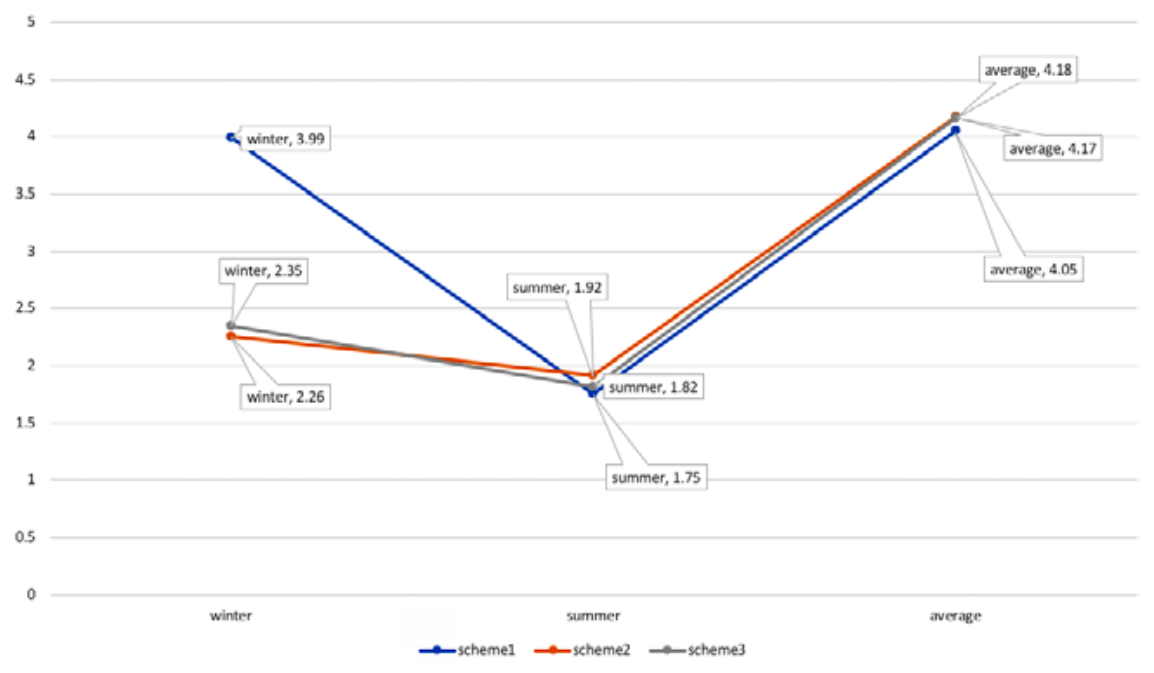

Figure 12. Comfort levels of schemes 1, 2, and 3 


\section{Conclusions}

This study compares and identifies the impacts of different tree-planting strategies and summarizes suggestions for landscape design to improve the wind environment in public spaces. The results of this study led to the conclusions.

(1) The effects of six different tree-planting combinations were calculated and compared based on CFD numerical simulation results. Planting trees of combination $\mathrm{A}$ and $\mathrm{B}$ in the public space can achieve the lowest average wind velocity leeward on winter days, while the combination $\mathrm{E}$ and $\mathrm{F}$ result in higher wind velocity, especially within the down-wind part of the trees, when compared with the other tree-planting combinations. The maximum length of leeward area is $20 \mathrm{~m}$ in combination $\mathrm{A}$, while the minimum is less than $10 \mathrm{~m}$ in combination F. Furthermore, the combinations $C$ and $D$ break the wind less effectively than $A$ and $B$ but have better ventilation in summer. The wind flow changes significantly with planted trees for different combinations.
(2) Three different planting schemes for the wind environment of Xuanwumen square were simulated. Accordingly, the body comfort level in different situations were calculated and analyzed. Scheme 2 scores the highest average comfort level in winter and summer, which is 4.18 out of 5 . However, the results revealed that the comfort level of scheme 2 scores the lowest winter when compared with other schemes. Thus the solution needs to balances the comfort of the wind environment in their time domains to optimize the public space environment.

These findings are beneficial for designing a comfortable environment in the hot-summer and coldwinter public space. Further studies should be carried out to focus on more detailed analysis of shape, branch height, combination with shrubs and herbs, in order to investigate in detail the effect of the tree planting forms for the outdoor comfort.

\section{References}

Chen, M., \& Yang, Z. (2014). 日照分析优化住区外部 活动场所设计研究——以鄂州市红莲湖某住宅规 划设计为例[Research on Optimizing the Design of External Activity Places in Residential Areas by Sunlight Analysis_- Taking the Planning and Design of a House in Honglian Lake, Ezhou City as an Example]. 华中建筑, 32(2), 40-44.

Feng, X., \& Chu, Y. (2017). 基于空气动力学模拟的城 市绿地局地微气候效应研究 [Study on local microclimate effects of urban green space based on aerodynamic simulations]. 中国园林, 33(4), 29-34.

Greens, S. R., Grace, J., \& Hutchings, N. J. (1995). Observations of turbulent air flow in three stands of widely spaced sitka spruce. Agricultural and Forest Meteorology, 74(3), 205-225. doi:10.1016/01681923(94)O2191-L

Huang, W. (2016). 基于风环境舒适度的沈阳市民 广场形态优化研究 [Research on optimization of Shenyang citizen square shape based on wind environment comfort]. Shenyang Jianzhu University, Shenyang.

Ivana Bajsanski Vesna Stojakovic Bojan Tepavcevic Marko Jovanovic Dejan Mitov. (2017). An application of the shark skin denticle geometry for windbreak fence design and fabrication. Journal of Bionic Engineering, 14(3), 579-587. doi:10.1016/S16726529(16)60423-7
Ke, Y. \& Sang, J. (2007). 小型绿化带对城市建筑物 周围风场影响的数值模拟[Numerical simulation of the impact of small green belts on wind fields around urban buildings]. 北京大学学报: 自然科学 版, 44(4), 585-591.

Li, Q., Meng, Q., \& Zhao, L. (2010). Numerical research on pedestrian wind environment around residential buildings in south china. Paper presented at the 299-303. doi:10.1109/ICAEE.2010.5557558

Lin, B. (2016). 城市滨水区更新风环境影响评价及优 化策略研究[Study on wind environment impact assessment and optimization strategy of urban waterfront renewal]. Chongqing University, Chongqing.

Liu, B. \& Si R. (2018). Adaptation Strategy of Wind Environment Landscape in Residential Area Based on Data Measurement and CFD Simulation--Taking Changwu Road Dormitory Area of Tongji University as an Example.中国园林, 34 (02): 24- 28.

Liu, J. (2005). 计算流体力学在城市规划设计中的应用 [Application of Computational Fluid Dynamics in Urban Planning and Design].东南大学学报: 自然 科学版, 35(A01), 301-304.

Tang, D., Hua, X., \& Wang, L. (2014).气候舒适度对旅 游业影响——以南京市为例[Correlation Analysis between Nanjing Climate Comfort and Inbound Passengers]. 统计与决策, (3), 119-122. 
Xu, Z. \& Han, L. (2018). 开放空间及周边的风环境历 史变化分析一一以南京为例[Analysis of Historical Changes of Wind Environment in Open Space and Surrounding Areas: A Case Study of Nanjing]. 城市 规划学, 2018 (02): 81-88.

Zeng Jing. (2015). 基于室外风环境优化的居住区种植 设计策略研究 [Study on planting design strategy of residential area based on outdoor wind environment optimization]. Sichuan Agricultural University, Chengdu.
Zhang, D. (2012).三维城市日照模拟分析及其应用研 究 [Three-dimensional urban sunshine simulation analysis and its application]. Hunan University of Science and Technology, Xiangtan.

Zhang, T. (2015).城市中心区风环境与空间形态耦合 研究 [Study on the coupling of wind environment and spatial morphology in urban central area]. Southeast University, China, Nanjing.

Zuo, X. \& Chu, K. (2003). 日照阴影辅助建筑环境设计 [Sunshine shadow aided architectural environment design].重庆建筑, (1), 28-30. 